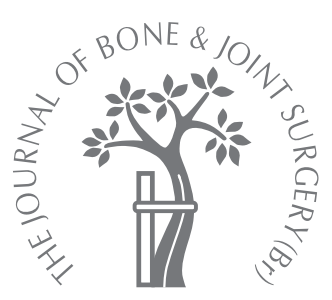

J. Girard, M. Lavigne, P.-A. Vendittoli, A. G. Roy

From The

Maisonneuve-

Rosemont Hospital, Université de Montréal, Montréal, Canada

\footnotetext{
I. Jirard, MD, Orthopaedic Surgeon

M. Lavigne, MD, FRCS,

Orthopaedic Surgeon

P.-A. Vendittoli, MD, MSc,

FRCS, Orthopaedic Surgeon

A. G. Roy, MD, FRCS,

Orthopaedic Surgeon

Department of Orthopaedics

Maisonneuve-Rosemont

Hospital, 5345 Boul

L'Assomption, Suite 55,

Montréal, Québec H1T 4B3,

Canada.

Correspondence should be sent to Dr M. Lavigne; e-mail: martin.lavigne@umontreal.ca

(C)2006 British Editorial Society of Bone and Joint Surgery doi:10.1302/0301-620X.88B6. $17447 \$ 2.00$
}

$J$ Bone Joint Surg [Br] 2006:88-B:721-6.

Received 23 November 2005;

Accepted 4 January 2006

\title{
Biomechanical reconstruction of the hip
}

\author{
A RANDOMISED STUDY COMPARING TOTAL HIP RESURFACING \\ AND TOTAL HIP ARTHROPLASTY
}

We have compared the biomechanical nature of the reconstruction of the hip in conventional total hip arthroplasty (THA) and surface replacement arthroplasty (SRA) in a randomised study involving 120 patients undergoing unilateral primary hip replacement. The contralateral hip was used as a control.

Post-operatively, the femoral offset was significantly increased with THA (mean 5.1 mm; -2.8 to 11.6) and decreased with SRA (mean $-3.3 \mathrm{~mm} ;-8.9$ to 8.2). Femoral offset was restored within SD $4 \mathrm{~mm}$ in $14(25 \%)$ of those with THA and in $28(57 \%)$ of the patients receiving SRA ( $p<0.001$ ). In the THA group, the leg was lengthened by a mean of $2.6 \mathrm{~mm}$ $(-6.04$ to +12.9$)$, whereas it was shortened by a mean of $1.9 \mathrm{~mm}(-7.1$ to +2.05$)$ in the SRA group, compared with the contralateral side. Leg-length inequality was restored within SD 4 $\mathrm{mm}$ in $42(86 \%)$ of the SRA and $33(60 \%)$ of the THA patients. The radiological parameters of acetabular reconstruction were similar in both groups.

Restoration of the normal proximal femoral anatomy was more precise with SRA. The enhanced stability afforded by the use of a large-diameter femoral head avoided overlengthening of the limb or increased offset to improve soft-tissue tension as occurs sometimes in THA. In a subgroup of patients with significant pre-operative deformity, restoration of the normal hip anatomy with lower pre-operative femoral offset or significant shortening of the leg was still possible with SRA.

Restoration of the normal anatomy of the hip at total hip arthroplasty (THA) provides better clinical function ${ }^{1-4}$ and abductor strength, ${ }^{1,2}$ as well as reduced wear of polyethylene. ${ }^{5}$ Failure to restore the normal anatomy at THA has been associated with a higher rate of dislocation, ${ }^{6}$ muscle weakness, ${ }^{4}$ limping, ${ }^{3}$ leg-length discrepancy, ${ }^{7}$ impingement and early loosening of the implant. ${ }^{8-12}$

To improve the precision of the anatomical reconstruction, the range of size of the implant has been increased and modular forms have been introduced to give different neck-shaft angles and offsets of the stem, lateralised acetabular inserts and femoral heads of larger diameter. Nevertheless, anatomical reconstruction of the hip at THA is not always easy. ${ }^{13-16}$

One means of optimising reconstruction of the anatomy is by total surface replacement arthroplasty (SRA). Earlier designs of SRA had high rates of failure, which were attributed to increased polyethylene wear with the largediameter head and secondary osteolysis. ${ }^{17}$ The use of metal-on-metal as the bearing surface with better wear properties meant that SRA gained in popularity for the treatment of young, active patients with degenerative disease of the hip. ${ }^{18-20}$ By removing less femoral bone than in conventional THA, the technique helped to preserve the proximal femoral anatomy. Therefore, it was thought that SRA would facilitate more precise biomechanical reconstruction of the hip.

To determine the validity of this assumption, we conducted a randomised study comparing the post-operative radiological biomechanical parameters of hip reconstruction by uncemented THA and hybrid SRA.

\section{Patients and Methods}

Patients aged over 18 years and under 65 years, suffering from advanced degeneration of the hip were screened by three orthopaedic surgeons (ML, PAV, AGR) working in the same institution for participation in the study, comparing the clinical outcome and survival of THA and SRA. They were enrolled if they were candidates for both THA and SRA and had none of the exclusion criteria (Table I). The patients were randomly assigned to either THA or SRA. A block randomisation table was created for each surgeon using SPSS 10.04 
Table I. Details of the exclusion criteria

One-stage bilateral total hip arthroplasty
Charnley class-C patients
Deep infection of the hip
Drug or alcohol abuse
Psychiatric illness
Pregnancy
Age (older than 65 years or younger than 18 years)
Hip arthrodesis
Neuromuscular disorder
Renal insufficiency
Known or suspected metal allergy
Known or suspected osteopenia or osteoporosis of the hip

software (SPSS Inc., Chicago, Illinois) and the results were kept in opaque, sealed envelopes. The study protocol was approved by the research ethics and scientific committees of our institution. All patients who participated in the study gave their written informed consent.

Between July 2003 and April 2005, 156 patients were operated on. There were 15 patients in the SRA group and 18 in the THA group who were excluded from the radiographic analysis because of previous surgery, anatomical deformity or severe osteoarthritis of the contralateral hip. Moreover, three patients who were scheduled for SRA were converted intra-operatively to THA with a large-diameter femoral head and were thus excluded from the radiographic analysis. All the remaining patients had at least one radiograph suitable for analysis. Thus, 120 patients with unilateral or mild bilateral osteoarthritis were included in the radiological study. Six patients in the THA group and ten in the SRA group with Perthes' disease or acetabular dysplasia were analysed as a separate deformed anatomy group. Therefore, the main study group consisted of 104 patients, 49 SRA and 55 THA.

All the operations were performed through a posterior approach. The Durom hip-resurfacing system (Zimmer, Winterthur, Switzerland) was used in the SRA group. The components were manufactured from Metasul high-carbon cobalt-chrome alloy (Zimmer). The femoral component had a wall $4 \mathrm{~mm}$ thick at the equator and $9 \mathrm{~mm}$ at the superior pole, a short alignment stem and internal recesses allowing controlled pressurisation of cement to produce a mantle of $0.75 \mathrm{~mm}$ to $1.5 \mathrm{~mm}$. The uncemented acetabular component subtended an angle of $165^{\circ}$ and had a uniform thickness of $4 \mathrm{~mm}$ with an external titanium vacuum plasma-spray coating of $250 \mu \mathrm{m}$.

For the THA group, the CLS Spotorno grit-blasted titanium uncemented femoral stem with a $28 \mathrm{~mm}$ Metasul femoral head was articulated with an Allofit uncemented acetabular cup and a Metasul cobalt-chrome polyethylene sandwich acetabular insert with an internal diameter of 28 $\mathrm{mm}$ (all Zimmer). The CLS stem had the option of two different neck-shaft angles $\left(135^{\circ}\right.$ and $\left.145^{\circ}\right)$, with increasing offset proportional to the stem size. A stem with a $125^{\circ}$ neck-shaft angle, which is now available, was not used in the study. The options for the neck length of the Metasul femoral head were $-4 \mathrm{~mm}$, neutral, $+4 \mathrm{~mm}$ and $+8 \mathrm{~mm}$.

Pre-operative planning with radiographic templating was carefully undertaken in all cases. ${ }^{14}$ The goal of reconstruction was to restore the normal centre of rotation of the hip, the femoral offset and the leg length, based on the normal contralateral hip.

Patients with unilateral or bilateral osteoarthritis with an asymptomatic contralateral hip (grade 0 or 1 ) according to Tönnis ${ }^{21}$ were selected for this radiological investigation. Patients with contralateral Tönnis grade- 2 and grade- 3 osteoarthritis, distorted contralateral anatomy due to previous surgery on the acetabulum or proximal femur, Perthes' disease, or acetabular dysplasia with joint dislocation or contralateral hip replacement were excluded (33 patients). Those with unilateral osteoarthritis caused by a deformity of the femur or acetabulum were considered as a separate group (Perthes' disease or acetabular dysplasia; 16 patients). Thus, patients selected for the radiological study were separated into a main group consisting of a homogenous population with unilateral degeneration of the hip (104 patients) and a group with unilateral deformed osteoarthritic hips (16 patients).

Standardised pre- and post-operative radiographs were analysed. Anteroposterior radiographs of the pelvis were taken with the legs positioned in $15^{\circ}$ of internal rotation. The radiographs were rejected if the coccyx was not centred on the pubic symphysis and located proximally within $2 \mathrm{~cm}$ to $4 \mathrm{~cm}$. This ensured proper positioning of the pelvis in both the frontal and sagittal planes. ${ }^{22}$ The best reproduced pre- and post-operative radiographs were selected for each patient.

These were scanned (VIDAR VXR-12, Herndon, Virginia) and analysed using Imagika software (Clinical Measurement Corporation, New Jersey) for valid and reliable measurements of the biomechanical parameters of the hip. ${ }^{23}$ The horizontal and vertical centres of rotation, the angle of inclination of the acetabular cup, the femoral offset and leg-length inequality were measured for the replaced and normal contralateral hip on post-operative radiographs (Fig. 1). The femoral neck-shaft angle was measured on post-operative radiographs of patients with SRA, as was the angle between the axis of the resurfacing femoral component and the anatomical axis of the femoral shaft (femoral component axis-shaft angle). The neck-shaft angle of the $135^{\circ}$ THA femoral stem was measured to assess the accuracy of positioning of the leg on post-operative radiographs. The reconstruction achieved by the three surgeons was compared to assess the variability of the surgical technique. Complete seating of the acetabular component was defined as the absence of a lucent line observed in the area of the dome of the implant.

Statistical analysis. All statistical analyses were performed using SPSS 10.04 software (SPSS Inc.). Proportions were compared by the chi-squared test. Mean differences between the THA and SRA groups were evaluated by Stu- 


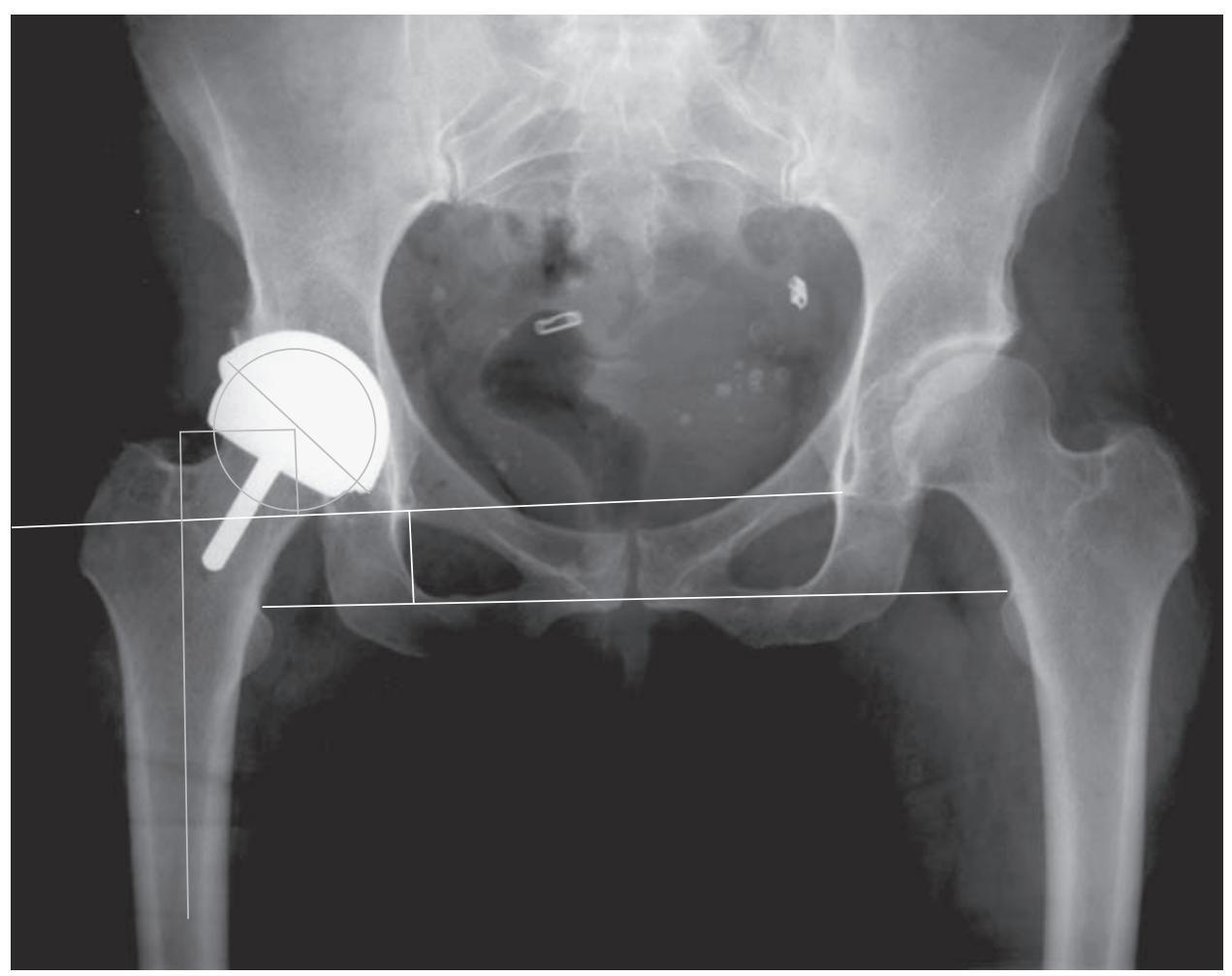

Fig. 1

Radiograph showing the biomechanical parameters. The inter teardrop line and a line perpendicular to the teardrop line passing through the centre of rotation of the hip was determined (vertical hip centre of rotation line). The vertical hip centre of rotation was determined by the perpendicular distance $(\mathrm{mm})$ from the centre of rotation of the hip to the inter-teardrop line. The horizontal centre of rotation was evaluated by the distance between the vertical centre of rotation line and the teardrop. Four points were determined on the longitudinal axis of the femoral shaft and the femoral shaft line was drawn. The femoral offset was evaluated by the perpendicular distance $(\mathrm{mm})$ from the centre of rotation to the femoral shaft line. Component inclination was evaluated by the angle $\left({ }^{\circ}\right)$ between the teardrop line and the component. The top of both lesser trochanters was identified and the lesser trochanter line was drawn. Limb length was evaluated by the perpendicular distance from the teardrop to the lesser trochanter line.

Table II. Mean (SD, range) pre-operative clinical and radiological data on patients in the main study group

\begin{tabular}{llll}
\hline & THA $^{*}$ (n = 55) & SRA $^{\dagger}$ (n = 49) & p value \\
\hline Male:Female & $34: 21$ & $31: 18$ & 0.6 \\
Age (yrs) & $48(16.5 ; 29.8$ to 64.9$)$ & $46.9(15.9 ; 25.4$ to 63.8$)$ & 0.7 \\
Body mass index & $29.6(6.2 ; 19.7$ to 48.1$)$ & $27.3(6.1 ; 17.6$ to 44.9$)$ & 0.06 \\
Leg-length inequality $(\mathrm{mm})$ & $-1.4(2.3 ;-10.4$ to +9.7$)$ & $-1.6(1.9 ;-5.4$ to +2.8$)$ & 0.12 \\
Contralateral femoral offset (mm) & $33.1(7.6 ; 12.7$ to 47.8$)$ & $33.9(6.9 ; 19.5$ to 46.8$)$ & 0.51 \\
Contralateral horizontal centre of rotation (mm) & $33.1(8.3 ; 23.3$ to 53.1$)$ & $35.2(6.7 ; 22.4$ to 51.4$)$ & 0.11 \\
Contralateral vertical centre of rotation $(\mathrm{mm})$ & $15.6(5.26 ; 4.8$ to 27.8$)$ & $16.5(4.4 ; 7.4$ to 31.1$)$ & 0.31 \\
\hline
\end{tabular}

* THA, total hip arthroplasty

† SRA, surface replacement arthroplasty

dent's $t$-test, as were measurements on the operated and control side within each group. The equality of variance was compared by Fisher's exact test. The mean differences between the three surgeons were compared by analysis of variance. Confidence intervals (CI) for the ratio of two SDs were computed by the F statistic. The level of significance was set at $p<0.05$ for all statistical analyses.

\section{Results}

The THA and SRA patients from the main study group had similar clinical and pre-operative radiological characteristics (Table II) and similar pre-operative diagnoses: osteoarthritis $(48 ; 87 \%$ vs $42 ; 86 \%)$, inflammatory arthritis $(4$; $7 \%$ vs $3 ; 6 \%)$ and avascular necrosis $(2 ; 4 \%$ vs $4 ; 8 \%)$, respectively. 
Table III. Biomechanical parameters of the operated hip in the main study group, compared with those of the normal contralateral hip. Data presented as mean (SD, range)

\begin{tabular}{lrlrl}
\hline & THA $^{*}$ (n = 55) & SRA & (n = 49) & p value \\
\hline Horizontal centre of rotation $(\mathrm{mm})$ & -3.1 & $(2.4 ;-7.1$ to +3.8$)$ & $-1.2(2.6 ;-5.9$ to +6.2$)$ & $<0.0001$ \\
Vertical centre of rotation $(\mathrm{mm})$ & 1.4 & $(3.7 ;-6.2$ to +11.2$)$ & $1.5(3.1 ;-7.4$ to +8.6$)$ & 0.2 \\
Acetabular component inclination $\left(^{\circ}\right)$ & 45.2 & $(5.6 ; 34.5$ to 55.7$)$ & $46.7(6.4 ; 31.2$ to 61$)$ & 0.2 \\
Femoral offset $(\mathrm{mm})$ & $5.1(3.2 ;-2.8$ to +11.6$)$ & $-3.3(2.6 ;-8.9$ to +8.2$)$ & $<0.0001$ \\
Leg-length inequality (mm) & $2.6(3.4 ;-6.04$ to +12.9$)$ & $-1.9(2.1 ;-7.1$ to +2.05$)$ & $<0.0001$ \\
\hline * THA, total hip arthroplasty & & & & \\
† SRA, surface replacement arthroplasty & & &
\end{tabular}

Table IV. Biomechanical parameters of the operated hip in the deformed anatomy group, compared with those of the normal contralateral hip. Data presented as mean (SD, range)

\begin{tabular}{|c|c|c|c|}
\hline & THA $^{*}(n=6)$ & $\operatorname{SRA}^{\dagger}(\mathrm{n}=10)$ & p value \\
\hline Horizontal centre of rotation $(\mathrm{mm})$ & $-3.7(1.8 ;-6.8$ to -2.3$)$ & $-2.3(1.7 ;-4.9$ to -1.1$)$ & 0.3 \\
\hline Vertical centre of rotation (mm) & $2.7 \quad(2.4 ; 0.1$ to 6.9$)$ & $2.3(1.8 ; 0.1$ to 5.9$)$ & 0.9 \\
\hline Acetabular component inclination $\left({ }^{\circ}\right)$ & $49.7(7 ; 42.2$ to 55.8$)$ & $43.9(6.0 ; 35.4$ to 54.3$)$ & 0.9 \\
\hline Femoral offset (mm) & $6.8(1.6 ; 4.8$ to 9.8$)$ & $-2.4(4.6 ;-8.9$ to +8.3$)$ & 0.0002 \\
\hline Leg-length inequality (mm) & $2.2(2.8 ;-0.9$ to +6.7$)$ & $-1.8(2.1 ;-7.0$ to +2.1$)$ & 0.5 \\
\hline
\end{tabular}

* THA, total hip arthroplasty

† SRA, surface replacement arthroplasty

The results of the measurement of the biomechanical parameters in the main study group and the deformed anatomy group are summarised below (Tables III and IV).

In the main study group, statistically significant differences between the three surgeons was found only for inclination of the acetabular component by one surgeon $\left(48^{\circ} \mathrm{vs}\right.$ $44.7^{\circ}$ and $\left.45.7^{\circ} ; \mathrm{p}=0.04\right)$. Incomplete seating of the component was observed in $10(18 \%)$ of patients with a THA and in $13(27 \%)$ of those with a SRA $(p=0.04)$. For the deformed anatomy group, a significant difference was seen only in the post-operative femoral offset ( $\mathrm{p}=0.002$ ).

Horizontal centre of rotation of the hip. The mean horizontal centre of rotation in both groups was statistically different $(p<0.0001)$, although the difference was only $1.9 \mathrm{~mm}$. The centre of rotation was significantly medialised in the THA $(\mathrm{p}<0.001)$ and SRA $(\mathrm{p}<0.001)$ groups. In each group $33(60 \%)$ of the THA and $41(84 \%)$ of the SRA patients were reconstructed within $\pm 3 \mathrm{~mm}$ of the normal contralateral side ( $\mathrm{p}=0.008)$.

Vertical centre of rotation of the hip. The mean vertical centre of rotation in both groups was not statistically different $(p=0.2)$. Compared with the normal contralateral side, the centre of rotation was significantly more proximal in the THA $(\mathrm{p}<0.001)$ and SRA $(\mathrm{p}<0.001)$ patients. In each group $40(73 \%)$ of the THA and $37(76 \%)$ of the SRA patients were reconstructed to within $\pm 3 \mathrm{~mm}$ of the normal contralateral side $(\mathrm{p}=0.74)$.

The angle of inclination of the acetabular component. The mean angle of inclination of the acetabular component in both groups was not statistically different $(p=0.2)$. The inclination lay between $35^{\circ}$ and $55^{\circ}$ in $53(96 \%)$ of those with a THA and in 45 (92\%) of the SRA patients.

Femoral offset. The mean post-operative femoral offset in both groups was statistically different $(p<0.0001)$. Compared with the normal contralateral side, the mean post- operative femoral offset was significantly increased by 5.1 $\mathrm{mm}$ in the THA patients $(\mathrm{p}<0.001)$ and decreased by 3.3 $\mathrm{mm}$ in those with SRA $(\mathrm{p}<0.001)$. This difference was statistically significant $(\mathrm{p}=0.0001)$. The $95 \% \mathrm{CI}$ for the mean difference in post-operative offset versus the normal contralateral side was $4.1 \mathrm{~mm}$ to $5.8 \mathrm{~mm}$ for THA patients and $-3.9 \mathrm{~mm}$ to $-2.6 \mathrm{~mm}$ for SRA patients. The post-operative femoral offset was increased in $47(85 \%)$ THA patients, compared with $4(8 \%)$ of those with SRA $(\mathrm{p}<0.001)$. The femoral offset was within $\pm 4 \mathrm{~mm}$ in $14(25 \%)$ with THA, compared with 29 (59\%) SRA patients $(\mathrm{p}<0.001)$.

Leg-length inequality. The mean post-operative leg-length inequality was $+2.6 \mathrm{~mm}(-6.04$ to +12.9$)$ in the THA group $(\mathrm{p}<0.001)$ and $-1.9 \mathrm{~mm}(-7.1$ to +2.05$)$ in the SRA ( $\mathrm{p}=$ 0.01 ) patients. The $95 \% \mathrm{CI}$ for the mean post-operative leg-length inequality was $1.8 \mathrm{~mm}$ to $3.6 \mathrm{~mm}$ for the THA patients and $-2.0 \mathrm{~mm}$ to $-1.0 \mathrm{~mm}$ for those with SRA. The length of the operated leg was increased compared with the normal contralateral side in $45(82 \%)$ of patients with a THA compared with $8(16 \%)$ in the SRA group $(\mathrm{p}<$ $0.001)$. The leg-length inequality was restored to within SD $4 \mathrm{~mm}$ in $33(60 \%)$ of those with a THA, compared with 42 $(86 \%)$ in SRA patients $(\mathrm{p}=0.002)$.

Neck-shaft angle and position of the femoral component. The mean normal femoral neck-shaft angle in the SRA group was $133.1^{\circ}\left(120.8^{\circ}\right.$ to $150^{\circ}$; SD 5.6). The mean SRA femoral component axis-shaft angle was $140.1^{\circ}\left(120.5^{\circ}\right.$ to $154.4^{\circ}$; SD 6.2). Therefore, the resurfacing femoral component was positioned on a mean of $7.1^{\circ}\left(-12.3^{\circ}\right.$ to $18.9^{\circ}$; SD 5.5) more valgus, with respect to the normal femoral neck-shaft angle. Of the THA femoral stems used, 53 (96\%) had a neck-shaft angle of $135^{\circ}$, the remainder being $145^{\circ}$. The mean neck-shaft angle measured for the $135^{\circ}$ THA femoral stem on post-operative radiographs was $136.5^{\circ}\left(129.5^{\circ}\right.$ to $139.8^{\circ}$; SD 2.5$)$. This was not significantly different from $135^{\circ}(\mathrm{p}>0.05)$. 


\section{Discussion}

Precise biomechanical reconstruction of the hip by THA is essential for the success of this procedure. ${ }^{9,24}$ In particular, a favourable clinical outcome is associated with optimal femoral offset and restoration of leg length. ${ }^{2-4,11,24}$ During THA part of the proximal femur is reconstructed with an implant which best reproduces the patient's anatomy and restores soft-tissue tension. To enable the surgeon to achieve this goal, different implant geometries, increased range of size, modularity of the implant and computer navigation systems are now available. Despite these improvements in design and surgical technique, anatomical reconstruction of the hip by THA remains a challenge, with poorly-reconstructed hips being associated with unsatisfactory outcome. ${ }^{4,6,8,12,25,26}$

SRA is viewed as a more anatomical procedure, since the small amount of bone resected from the femoral head leaves the proximal femur virtually intact. One proposed advantage of this technique is the easier reconstruction of the normal anatomy, which could ultimately translate into a better clinical outcome.

Two studies comparing biomechanical reconstruction by SRA and THA were published recently. ${ }^{27,28}$ Silva et $\mathrm{al}^{28}$ compared pre- and post-operative radiographs of an unmatched series of 19 THAs and 22 SRAs performed by one surgeon. Compared with the normal contralateral side, the post-operative leg length was shorter by a mean of 2.2 $\mathrm{mm}$ in SRA and $1.1 \mathrm{~mm}$ in THA ( $\mathrm{p}=0.88$ ). Femoral offset was reduced by $8.4 \mathrm{~mm}$ in SRA and increased by $5.2 \mathrm{~mm}$ in THA $(\mathrm{p}<0.0001)$. The precision of reconstruction in both groups was not reported. The authors concluded that THA may be more suitable than SRA in the presence of pre-operative leg-length inequality of more than $10 \mathrm{~mm}$, or a comparatively low femoral offset.

Loughead et $\mathrm{al}^{27}$ reviewed the post-operative radiographs of unmatched THAs (26) and SRAs (28) performed by a single surgeon. The operated side was compared with the uninvolved contralateral hip. The centre of rotation of the acetabulum after operation was different in both groups; $3.5 \mathrm{~mm}$ more medial and $4 \mathrm{~mm}$ more superior in THA versus $2.1 \mathrm{~mm}$ more lateral and $0.5 \mathrm{~mm}$ more inferior in SRA. The mean leg length was increased on the operated side in both groups, $3.9 \mathrm{~mm}$ in THA patients versus $0.3 \mathrm{~mm}$ in those with SRA $(\mathrm{p}<0.0001)$, whereas the mean femoral offset increased by $0.6 \mathrm{~mm}$ after THA and decreased by 4.5 $\mathrm{mm}$ after SRA $(\mathrm{p}<0.0001)$. They concluded that hip biomechanics were more accurately restored by THA. We believe this conclusion to be misleading, since they reported increased femoral offset and leg lengthening after THA, both of which were compensated for by superior and medial placement of the acetabular component. Therefore, the normal biomechanics were not truly restored more accurately with THA.

Our study compared the biomechanics of the hip in two homogenous groups of patients. Valid retrospective comparison of consecutive cohorts of THA and SRA patients is difficult because of the bias introduced by different criteria for patient selection for both procedures. Randomised clinical trials remain the study of choice to evaluate the outcome of different treatment options. ${ }^{17}$ Our study involved three surgeons, which improves the generalisation of the results.

Unlike Loughead et $\mathrm{al}^{27}$ we achieved a similar position of the acetabular component in both groups, enabling direct comparison of the precision of femoral reconstruction by SRA and THA. Slightly less medialisation $(-1.2 \mathrm{~mm}$ for SRA vs $-3.1 \mathrm{~mm}$ for THA, $\mathrm{p}<0.001$ ) was attained with the thicker SRA acetabular component. In addition, incomplete seating was seen more frequently in SRA $(13 ; 27 \%$ of SRA vs $10 ; 18 \%$ of THA patients), probably due to a peripheral press-fit of $3 \mathrm{~mm} v$ s $2 \mathrm{~mm}$ for the THA acetabular component and the absence of holes, which did not allow visualisation of its seating.

On the femoral side, we noted a more precise restoration of anatomy with SRA. Leg length was restored to within $\pm 4 \mathrm{~mm}$ in $33(60 \%)$ of THA and $42(86 \%)$ of SRA patients $(\mathrm{p}=0.002)$. Femoral offset was restored to within $\pm 4 \mathrm{~mm}$ in $14(25 \%)$ of THA and $29(59 \%)$ of SRA $(\mathrm{p}<0.001)$. The $95 \%$ CIs of the mean and standard deviation for both leglength inequality and femoral offset were smaller with SRA, reflecting the more predictable reconstruction achieved.

The less precise reconstruction of the normal anatomy after resecting the proximal femur in THA and occasional suboptimal stability may account for over-lengthening of the leg and increased femoral offset after THA to improve the stability. In SRA, the large-diameter head affords stability so that compensation for soft-tissue laxity or impingement by over-lengthening the leg, or increasing the offset is less likely.

Although the number of patients in the deformed anatomy group was small and the deformities were not severe, reconstruction by SRA was comparable to that by THA, except for femoral offset. There was no statistical difference in any of the measurements in the deformed anatomy group (both SRA and THA) in comparison with the main study group. All deformities secondary to joint subluxation could be corrected by SRA.

Restoring or increasing femoral offset is thought to be critical in THA in influencing wear, ${ }^{1,9,26}$ although one study failed to confirm this assumption. ${ }^{29}$ Improved femoral offset seems to increase the force-generating capacity of the abductor muscle, ${ }^{2,4,30}$ although a laboratory investigation of gait in THA with two different offsets reported more physiological walking with a low-offset femoral stem. ${ }^{25}$ One unequivocal benefit of the restoration of offset in THA seems to be the improved stability of the components. ${ }^{31,32}$ In SRA, under-restoration of femoral offset is likely to occur in most cases. However, unlike THA, this may be advantageous in SRA. As demonstrated by other authors, ${ }^{27,28}$ we observed a statistically significant mean decrease of 3.3 $\mathrm{mm}$ in femoral offset with SRA. This is inherent to the preferential valgus positioning of the femoral component, aver- 
aging $7.1^{\circ}$ in our study. To increase femoral offset in SRA, the femoral component should be positioned proud on the femoral neck, leaving cancellous bone exposed at the junction of the head and neck, which would augment tensile stresses on the lateral femoral neck, thus heightening the risk of fracture. Positioning the femoral component in varus with the goal of increasing femoral offset is subject to failure. ${ }^{33}$ Despite reducing femoral offset, valgus positioning of the femoral component favours compressive stresses under the component which are crucial to the long-term stability of the implant. ${ }^{34}$ Moreover, this decrease in femoral offset reduces the lever arm of the abductor muscles. Consequently, the force generated by the pull of the abductor muscle must increase in order to balance movement of the body, thus generating more compressive stresses on the lateral femoral neck which neutralise tensile stresses. ${ }^{35}$ Although theoretically this may elevate joint reaction forces, the influence on wear of the metal-on-metal articulation used in modern SRA should be minimal, especially with reduction of only $3.3 \mathrm{~mm}$ in femoral offset. Finally, the excellent clinical outcome reported, coupled with the low rate of dislocation of SRA, does not suggest that a slight loss of femoral offset is as detrimental in SRA as in THA. ${ }^{2,3,5,19,20}$ It should be appreciated that valgus positioning of the femoral component also facilitates leg lengthening, which is usually needed to equalise the length in SRA.

Biomechanical reconstruction of the femur is more reproducible with SRA because the anatomy of the hip is less distorted during surgery and better stability is afforded by the large-diameter femoral head. With SRA, leg length is more easily restored to normal, and although femoral offset was slightly reduced, more precise reconstruction of the mechanics was achieved by SRA. We believe that the reduction in femoral offset inherent to SRA is advantageous biomechanically, and does not affect the clinical outcome. Restoration of normal anatomy in patients with lower preoperative femoral offset or significant shortening of the leg is still possible to some extent with SRA, as shown in our deformed anatomy group.

No benefits in any form have been received or will be received from a commercial party related directly or indirectly to the subject of this article.

\section{References}

1. Yamaguchi T, Naito M, Aasayama I, Ishiko T. Total hip arthroplasty: the relationship between posterolateral reconstruction, abductor muscle strength, and femoral offset. J Orthop Surg (Hong Kong) 2004;12:164-7.

2. McGrory BJ, Morrey BF, Cahalan TD, An KN, Cabanela ME. Effect of femoral offset on range of motion and abductor muscle strength after total hip arthroplasty. $J$ Bone Joint Surg [Br] 1995;77-B:865-9.

3. Asayama I, Naito M, Fujisawa M, Kambe T. Relationship between radiographic measurements of reconstructed hip joint position and the Trendelenburg sign. J Arthroplasty 2002;17:747-51.

4. Asayama I, Chammongkich S, Simpson KJ, Kinsey TL, Mahoney OM. Reconstructed hip joint position and abductor muscle strength after total hip arthroplasty. J Arthroplasty 2005;20:414-20.

5. Sakalkale DP, Sharkey PF, Eng K, Hozack WJ, Rothman RH. Effect of femoral component offset on polyethylene wear in total hip arthroplasty. Clin Orthop 2001; 388:125-34
6. Jolles BM, Zangger P, Leyvraz PF. Factors predisposing to dislocation after primary total hip arthroplasty: a multivariate analysis. J Arthroplasty 2002;17:282-8.

7. Woolson ST, Hartford JM, Sawyer A. Results of a method of leg-length equalization for patients undergoing primary total hip replacement. J Arthroplasty 1999;14: 159-64.

8. Kelley SS. High hip center in revision arthroplasty. J Arthroplasty 1994;9:503-10.

9. Charnley J. Low friction arthroplasty of the hip: theory and practice. Vol 3. New York: Springer-Verlag, 1979

10. Bourne RB, Rorabeck CH, Patterson JJ, Guerin J. Tapered titanium cementless total hip replacements: a 10- to 13-year follow-up study. Clin Orthop 2001;393: 112-20.

11. Konyves A, Bannister GC. The importance of leg length discrepancy after total hip arthroplasty. J Bone Joint Surg [Br] 2005;87-B:155-7.

12. Steinberg B, Harris WH. The offset problem in total hip arthroplasty. Contemp Orthop 1992;24:556-62

13. Johnston RC, Brand RA, Crowninshield RD. Reconstruction of the hip: a mathematical approach to determine optimum geometric relationships. J Bone Joint Surg [Am] 1979;61:639-52.

14. Bourne RB, Rorabeck CH. Soft tissue balancing: the hip. J Arthroplasty 2002;17 (Suppl 1):17-22.

15. Lindgren JU, Rysavy J. Restoration of femoral offset during hip replacement: a radiographic cadaver study. Acta Orthop Scand 1992;63:407-10.

16. Sakai T, Sugano N, Ohzono K, et al. Femoral anteversion, femoral offset, and abductor lever arm after total hip arthroplasty using a modular femoral neck system. J Orthop Sci 2002;7:62-7.

17. Howie DW, McGee MA, Costi K, Graves SE. Metal-on-metal resurfacing versus total hip replacement: the value of a randomized clinical trial. Orthop Clin North Am 2005;36:195-201

18. Sieber HP, Rieker CB, Kottig P. Analysis of 118 second-generation metal-on-metal retrieved hip implants. J Bone Joint Surg [Br] 1999;81-B:46-50.

19. Amstutz HC, Thomas BJ, Jinnah R, et al. Treatment of primary osteoarthritis of the hip: a comparison of total joint and surface replacement arthroplasty. $J$ Bone Joint Surg [Am] 1984;66-A:228-41.

20. McMinn D, Treacy R, Lin K, Pynsent P. Metal on metal surface replacement of the hip: experience of the McMinn prosthesis. Clin Orthop 1996;329(Suppl):89-98.

21. Tönnis D. Clinical and radiographic schemes for evaluation therapeutic results. In: Congenital dysplasia and dislocations of the hip in children and adults. Berlin: Springer-Verlag, 1987:165-71.

22. Tannast M, Zheng G, Anderegg C, et al. Tilt and rotation correction of acetabular version on pelvic radiographs. Clin Orthop 2005;438:182-90.

23. Girard J, Touraine $\mathbf{D}$, Soenen $\mathbf{M}$, et al. Measurement of head penetration on digitalized radiographs: reproducibility and accuracy. Rev Chir Orthop Reparatrice Appar Mot 2005;91:137-42 (in French).

24. Charles MN, Bourne RB, Davey JR, et al. Soft-tissue balancing of the hip: the role of femoral offset restoration. Instr Course Lect 2005;54:131-41.

25. Hodge WA, Andriacchi TP, Galante J0. A relationship between stem orientation and function following total hip arthroplasty. J Arthroplasty 1991;6:229-35.

26. Devane PA, Robinson EJ, Bourne RB, et al. Measurement of polyethylene wear in acetabular components inserted with and without cement: a randomized trial. J Bone Joint Surg [Am] 1997;79-A:682-9.

27. Loughead JM, Chesney D, Holland JP, McCaskie AW. Comparison of offset in Birmingham hip resurfacing and hybrid total hip arthroplasty. J Bone Joint Surg [Br] 2005;87-B:163-6.

28. Silva M, Lee KH, Heisel C, Dela Rosa MA, Schmalzried TP. The biomechanical results of total hip resurfacing arthroplasty. J Bone Joint Surg [Am] 2004;86-A:40-6.

29. Ebied A, Hoad-Reddick DA, Raut V. Medium-term results of the Charnley low-offset femoral stem. J Bone Joint Surg [Br] 2005;87-B:916-20.

30. Delp SL, Wixson RL, Komattu AV, Kocmond JH. How superior placement of the joint center in hip arthroplasty affects the abductor muscles. Clin Orthop 1996;328: $137-46$.

31. Fackler CD, Poss R. Dislocation in total hip arthroplasties. Clin Orthop 1980;151: 169-78.

32. Dennis DA, Lynch CB. Stability advantages of a modular total hip system. Orthopedics 2005;28 (Suppl):1049-52.

33. Beaule PE, Dorey DJ, LeDuff M, Gruen T, Amstutz HC. Risk factors affecting outcome of metal-on-metal surface arthroplasty of the hip. Clin Orthop 2004;418:87-93.

34. Freeman MA. Some anatomical and mechanical considerations relevant to the surface replacement of the femoral head. Clin Orthop 1978;134:19-24.

35. Davey JR, O'Connor DO, Burke DW, Harris WH. Femoral component offset: its effect on strain in bone-cement. J Arthroplasty 1993;8:23-6. 